\title{
Audácia baseada em evidências
}

\section{Audacity based on evidence}

Audacia basada en la evidencia

Isabella Talita Landim da Silva Santos ${ }^{\mathrm{a}}$, Thiago Rocha de Pontes ${ }^{\mathrm{b}}$, Renato Matias Dantas ${ }^{\mathrm{a}}$, Nelson Barros Pinheiro Neto ${ }^{\mathrm{a}}$

"Medicamentos mortais e crime organizado: como a indústria farmacêutica corrompeu a assistência médica" (Porto Alegre, Bookman, 2016), do médico pesquisador Peter $\mathrm{C}$. Gøtzsche, defende veementemente a ideia de que a indústria farmacêutica trata-se de uma verdadeira máfia criminosa. A obra é dividida em 22 capítulos, de modo que cada um é seguido das referências as quais os corroboram, é escrita de forma clara, precisa e embasada em fatos, sendo que muitos desses foram vivenciados pelo próprio autor.

A priori, o autor faz referência a sua infância e ao seu avô médico, a quem sempre respeitou e, no entanto, de quem discordava no tocante às prescrições medicamentosas e à carência de atualização nos estudos depois da graduação. Durante a adolescência, cogitou ser engenheiro de rádio, engenheiro eletricista, psicólogo, mas tinha grande interesse por biologia, chegando a cursar e a tornar-se professor dessa área. Trabalhou também como representante farmacêutico e, nesse percurso, amadureceu o pensamento crítico em relação à ilegalidade que permeia não apenas a introdução de medicamentos para indicações não aprovadas, mas também a apresentação de pesquisas preliminares a médicos sem um ensaio clínico definitivo. Nessa esfera, relata a relevância da criação da Colaboração Cochrane, a qual foi fundada para combater as pesquisas médicas tendenciosas, através de revisões sistemáticas rigorosas dos ensaios randomizados.

Ao trilhar uma filosofia pessoal de vida, resolveu começar a decidir por si mesmo: em 1978 começou a cursar Medicina, enquanto ainda trabalhava na Astra-Syntex, onde era responsável por ensaios clínicos e solicitação de registros para novos medicamentos e indicações. Em referência ao modelo de negócio das empresas farmacêuticas, Gøtzsche afirma que há um verdadeiro crime organizado, levando médicos e pacientes a acreditarem na eficiência e segurança dos medicamentos, com base na falsa ideia de testes cuidadosos por parte da indústria farmacêutica e exames minuciosos pelas agências reguladoras.

Fonte de financiamento: declaram não haver.

Parecer CEP:

não se aplica.

Conflito de interesses: declaram não haver Procedência e revisão por pares: revisado por pares. Recebido em: 15/04/2017. Aprovado em: 01/05/2017. 
O autor concorda com o pensamento de Paracelsius sobre a dose ser a diferença entre o veneno e o medicamento e, para ilustrar essa tese, traz o exemplo da toxina botulínica: a neurotoxina produzida pela bactéria Clostridium botulinum é um dos venenos mais fortes da natureza, de modo que uma dose de 50ng matou metade dos macacos em um estudo de toxicidade, todavia, é utilizada por humanos para tratar rugas entre as sobrancelhas. Muito embora a bula advirta sobre o risco de morte, pela possibilidade de absorção pela mucosa do olho, o uso da toxina botulínica é bem comum.

Ao realizar pesquisas na internet no tocante às empresas farmacêuticas e fraudes, encontrou dez ações fraudulentas recentes (entre 2007 e 2012): pagamento de propinas e oferecimento de hospitalidade suntuosa a médicos que prescrevessem alguns medicamentos por parte da Pfizer; comércio ilícito de oxcarbazepina pela Novartis; superfaturamento com medicamentos destinados a pacientes indigentes por parte da Sanofi-Aventis; comércio ilegal de medicamentos off-label pela GlaxoSmithKline; entre outras.

Em conformidade com suas pesquisas, afirma categoricamente que o crime corporativo é comum e os delitos são repetitivamente executados, o que leva a muitas mortes e a inúmeros danos sérios. No que tange ao benefício dos medicamentos, Peter considera que poucos são os pacientes os quais se beneficiam integralmente, usando a depressão como exemplo para defender esse posicionamento, já que no seu centro de pesquisas são utilizados - dentre outros - medicamentos antidepressivos.

Explica como é feito um estudo duplo cego e que um não cegamento de um estudo com placebo, por menor que seja, pode transformar um medicamento totalmente ineficaz em um que pareça ser muito eficaz. Para ele, o ensaio clínico randomizado é o delineamento mais fidedigno para avaliar tratamentos. Nesse sentido, ele adverte como imoral: médicos e pacientes ajudam as empresas com seus ensaios, sem haver reciprocidade. Além disso, é deveras comum a manipulação de ensaios clínicos a fim de que os resultados se tornem úteis e lucrativos para os vendedores.

Outro fato que choca o autor é a aliança existente entre grandes indústrias do ramo farmacêutico e as academias de Medicina: para exemplificar, relata que em 2003 pesquisadores das faculdades de Medicina publicaram resultados positivos sobre o uso de inibidores seletivos de recaptação de serotonina em crianças e adolescentes, no entanto, a Food and Drug Administration (FDA) determinou a existência do risco de suicídio com o uso desses inibidores.

Ademais, Gøtzsche denuncia, com dados verídicos, questões relacionadas a conflito de interesse; à influência corruptora do dinheiro fácil; aos ensaios de semeadura, através dos quais os médicos recebem medicamentos novos das empresas e são convidados a usá-los em seus pacientes e, em boa parte dos casos, usam medicamentos novos e caros em detrimento dos antigos e baratos, mas igualmente eficazes; ao marketing disfarçado nos ensaios clínicos; à venda agressiva; à regulação impotente de medicamentos e o envolvimento de muitos políticos; à inacessibilidade por parte de médicos e pacientes de todos os dados gerados pelos ensaios clínicos. Refere-se também à psiquiatria e à facilidade em manipular as definições de transtornos psiquiátricos, de modo que os psiquiatras estão sob um alto risco de corrupção e esse ramo da Medicina tornou-se uma mina de ouro para a indústria farmacêutica.

Para finalizar a obra, o autor alerta para o fato de que grandes reuniões envolvendo o corpo médico são financiadas pelas corporações farmacêuticas e cita uma participação em uma palestra, na qual abordou fraudes associadas aos cinco patrocinadores do evento em questão. Adverte, tal como fez durante todo o 
livro, que a indústria farmacêutica é a pior de todas as indústrias, em razão de agir como crime organizado, infringindo a lei e ceifando a vida de milhares de inocentes.

Analisando-se a obra em questão, vale destacar que a linguagem de Gøtzsche é clara, direta e forte. Trata-se de um livro sem concessões, dissimulações e arrodeios; além de contar com uma série de referências que comprovam os fatos e as evidências (a esmagadora maioria delas são detalhadas) utilizados como argumentos. É notório, assim, que não falta ao autor coragem em expor de uma forma tão aberta a corrupção transpassada no meio farmacêutico e médico. Talvez vários outros pesquisadores do cenário apresentado sejam cientes dessa problemática e até podem ter vontade em abordá-la e, no entanto, não o fazem.

Audácia e franqueza são ingredientes que Peter demonstrou ter em abundância. Como contribuintes desse modelo desmoralizante, o autor aponta médicos envolvidos com consultorias, palestras e experimento irregular de medicamentos e, em decorrência disso, é pouco provável que não apenas esses profissionais mas também os acadêmicos de Medicina leiam o livro e não sintam ao menos um incômodo quanto a sua colocação frente a essa lamentável realidade.

Convém, por conseguinte, o incentivo dessa leitura por parte desses grupos até mesmo como mecanismo de combate à comercialização da assistência médica pela máfia do mercado farmacêutico. É louvável perceber que - além de criticar e desmascarar a indústria abordada - o autor mostra as possíveis soluções para arrostarem esse tipo de prática criminal.

Gøtzsche apresenta propostas e urge por uma revolução, deixando explícito o seu parecer no que tange ao combate contra essa mazela social: deve-se potencializar o processo de regulação, a fim de transformá-lo em um sistema mais transparente, independente e até mesmo eficientemente investigativo; adicionando-se também a prática da Medicina baseada - de forma real - em evidências; além da disponibilização de todos os dados para licenciar medicamentos, somada à exposição de vínculos financeiros que permeiam a indústria farmacêutica.

É previsível, assim, mediante a exposição de Peter tão bem consolidada em argumentos e fatos sólidos, que o ramo das associações farmacêuticas articule-se em prol de enfraquecer ou derribar a ideia de criminalização desse meio; ora, essa obra é uma arma de boa munição contra a cegueira que há por trás da ideia de que os medicamentos a que temos acesso apenas curam enfermidades e salvam vidas.

Inegavelmente, esse livro é de extrema valia para a construção de um posicionamento crítico de profissionais da saúde, sobretudo de médicos e estudantes de Medicina. A leitura da obra, por fim, deve ser estimulada, em virtude de, muito provavelmente, poder contribuir para a qualidade da prática médica, enriquecendo-a com honestidade, ética e compromisso social.

Peter Christian Gøtzsche, dinamarquês, 67 anos, além de mestre em biologia e química, é especialista em medicina interna, cofundador da Colaboração Cochrane e fundador do The Nordic Cochrane, professor de Delineamento e Análise de Pesquisa Clínica da Universidade de Copenhagen. Publicou mais de 50 artigos e escreveu outros livros: "Mammography Screening: truth, lies and controversy", "Rational Diagnosis and Treatment: evidence-based clinical decision-making", "On Safari in Kenya", "Rationel klinik. Evidens diagnostiske og terapeutiske beslutninger". 
a Universidade Federal de Campina Grande (UFCG). Campina Grande, PB, Brasil. isabellatalitalandim@gmail.com (Autora correspondente); renatomd3@gmail.com; nelson.bpn@gmail.com

b Faculdade Maurício de Nassau (UNINASSAU). Natal, RN, Brasil. thiagorpontes@ hotmail.com 